\title{
СТРАТИГРАФИЧЕСКИЕ ПРОБЕЛЫ В РАЗРЕЗЕ ВЕНДА И КЕМБРИЯ СЕВЕРНОИ ПРИБАЛТИКИ
}

Разработка иерархической классификации стратиграфических пробелов (Пиррус, Әйнасто, 1987) создала основу для регистрации и систематизации всех основных пропусков в последовательности слоев в реальных осадочных толщах палеозоя Прибалтики. Обработка материала на основе этой классификационной схемы позволяет апробировать и доработать предложенную классификацию, с одной стороны, и получить представление о реальных соотношениях геологических явлений данной категории с учетом ранга их значимости, с другой. Первые результаты такого анализа по вендскому и кембрийскому разрезу Прибалтики составляют предмет данного сообщения.

Для соответствующего анализа был составлен вариант стратиграфической схемы по выявлению вопросов, связанных с пробелами между стратиграфическими подразделениями Прибалтики. В отличие от традиционных стратиграфических схем, реально существующие геологические тела оставлены здесь без текстовых и краповых обозначений и специальным крапом, соответствующим рубрикации предложенной классификации пробелов (Пиррус, Әйнасто, 1987) обозначены поля пропусков между ними (рисунок). Горизонтальная шкала рисунка базируется на структурно-фациальном районировании территории Прибалтики в венде и кембрии (Брангулис и др., 1974). Вертикальная шкала, которая должна обеспечить разбивку рисунка на соизмеримые возрастные интервалы по вертикали, выбрана несколько иная, чем в принятой стратиграфической схеме, так как подразделение разрезов позднего венда и раннего кембрия, разработанное на биостратиграфической основе, главным образом, по зональности эволюции комплексов акритарх (Решения . ., 1978; Стратиграфия..., 1979) не устраивает в данном отношении: выделяемые горизонты слишком неравноценны по своему объему. Поэтому был использован другой путь. Исходя из новейших данных по определению длительности вендского и кембрийского периодов и их основных подразделений (Харленд и др., 1985), был выбран условный шаг - хроностратон продолжительностью 5-6 млн. лет, на который полностью делится весь изучаемый разрез. Выделяемый хроностратон в одних случаях близок к горизонту или его отдельным частям, в других - к одной или двум трилобитовым зонам (средний и верхний кембрий), в третьих - к определенным фазам развития бассейнов седиментации (венд). Несмотря на большие условности при сопоставлении этих хроностратонов с конкретными геологическими подразделениями разреза, получаемая школа все же принципиально важна: она позволяет более полно отражать объемы стратиграфических пробелов, которые на обычных стратиграфических схемах, как правило, сильно редуцируются.

По предложенной шкале в поздневендской части разреза, где по данным палеомикрофитологического анализа можно выделить лишь два горизонта - редкинский и котлинский (Стратиграфия..., 1979), выде- 


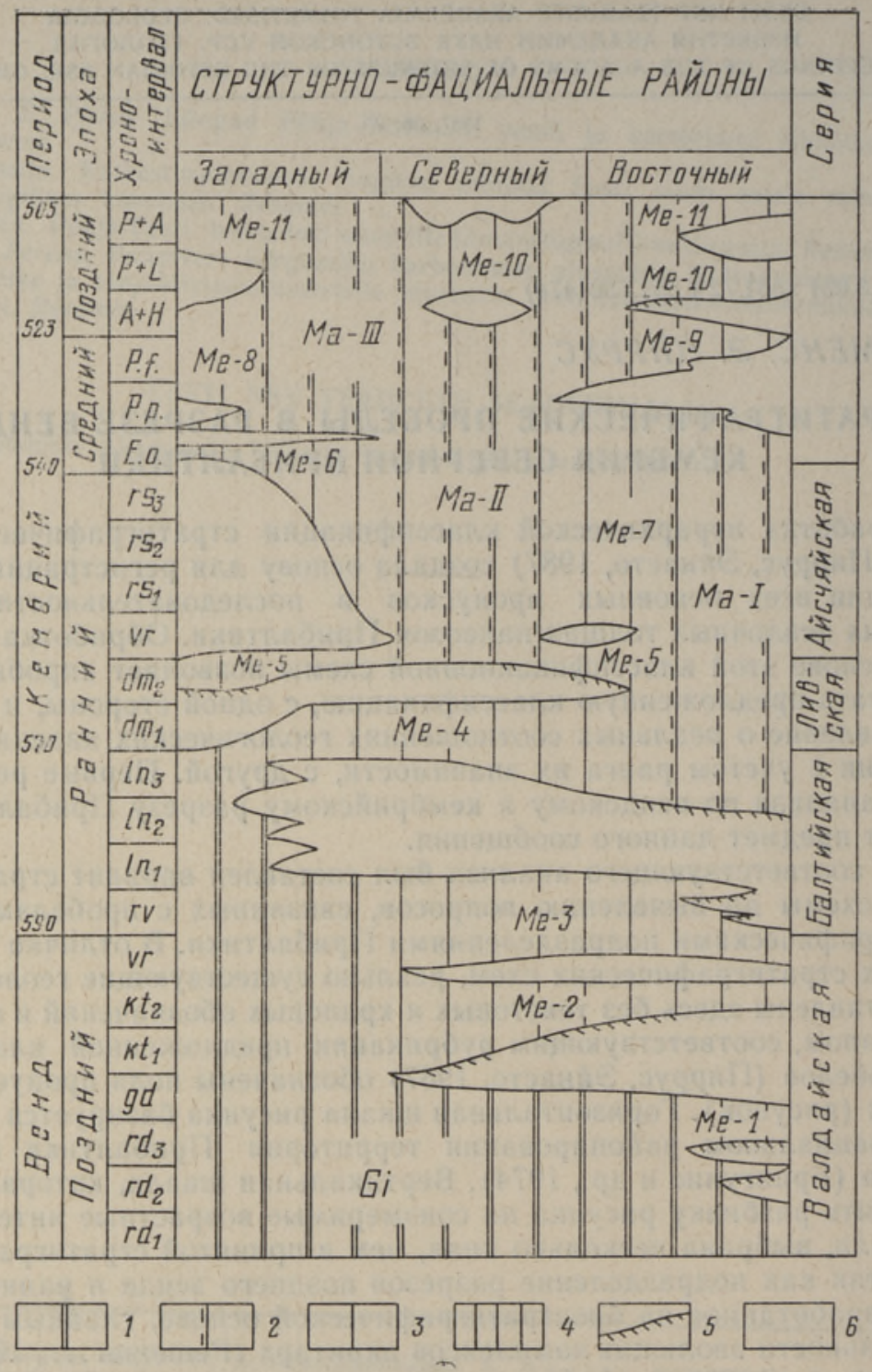

Соотношение основных стратиграфических пробелов и реально сохранившихся геологических тел в разрезе венда и кембрия Северной Прнбалтикн.

1 - гигапробелы, 2 - макропробелы, 3 - мезопробелы, 4 - микропробелы, 5 - коры и зоны выветривания, 6 - литотела.

$\mathrm{X}$ ронои н те рв ал ы венд а: $\mathrm{rd}_{1}-$ нижний цикл редкинского горизонта, $\mathrm{rd}_{2}-$ средний цикл, $\mathrm{rd}_{3}$ - верхний цикл, $\mathrm{gd}$ - формирование отложений гдовской свиты, $\mathrm{kt}_{1}-$ трансгрессивнал фаза формирования котлинской свиты, $\mathrm{kt}_{2}-$ регрессивная фаза формирования котлинской свиты, vr - формирование отложений воронковской свиты; х ро н о инте рв алы кем бр и я: rv - формирование отложений ровенского горизонта, $\ln _{1}$ - начало трансгрессин лонтоваского этапа, $\ln _{2}$ - трансгрессивный максимум лонтоваского этапа осадконакопления, $\mathrm{ln}_{3}$ - регрессия лонтоваского моря, $\mathrm{dm}_{1}$ - формнрование отложений сыруской свиты доминопольского горизонта, $\mathrm{dm}_{2}-$ формирование отложений люкатиской и тискреской свит доминопольского горизонта, $\mathrm{vr}$ - формирование отложений вергальского горизонта, $\mathrm{rs}_{1}+\mathrm{rs}_{2}+\mathrm{rs}_{3}$ - формирование отложений раусвеского горизонта.

Е. о. - надзона Eccoparadoxides oelandicus, Р. p. - надзона Paradoxides paradoxissimus, P. f. - надзона Paradoxides forhhammeri, A + H - зоны Agnostus н Homagnostus, $\mathrm{P}+\mathrm{L}$ - зоны Parabolina spinulosa и Leptoplastus, $\mathrm{P}+\mathrm{A}$ - зоны Peltura и Acerocara. 
ляется 7 хроностратонов, каждый в объеме отложений отдельных фаз редкинского и котлинского этапов осадконакопления. Также можно подразделить балтийский этап осадконакопления на 4 хроноинтервала, которые хорошо согласуются с отдельными фазами развития осадконакопления и с новыми материалами по биостратиграфическому расчленению горизонтов серии (Пашкявичене, 1981; Менс, Пости, 1984).

Такой подход к соотношению геологического времени с выделяемыми стратиграфическими подразделениями в постбалтийской части раннего кембрия вызывает некоторые затруднения. Так, по стратиграфической схеме кембрийских отложений Восточно-Европейской платформы данная часть разреза расчленяется на три горизонта - доминопольский, вергальский, раусвеский. Нижние два - доминопольский и вергальский - относятся по принятой корреляции к «зоне Holmia», а верхний - раусвеский к «зоне Protolenus», т. е. к подразделениям, образовавшимся соответственно в течение атдабанского и ленского веков по шкале геологического времени У. В. Харленда и др. (1985). Поскольку длительность обоих веков около 15 млн. лет, то, исходя из строения разреза и этапности осадконакопления во второй половине раннего кембрия (Менс, 1981), время формирования ливской серии целесообразно отразить в объеме двух хроноинтервалов, а вергальского горизонта - в объеме одного. Аналогично, к раусвескому горизонту (=ленский ярус) следует отнести все оставшиеся 15 млн. лет, т. е. три соизмеримых хроноинтервала, что, однако, не покрывается реальными отложениями соответствующей мощности при литологически непрерывной последовательности наслоения. Поэтому принятое решение (рисунок) вызывает некоторые сомнения, оно является предварительным и весьма условным, подлежащим корректировке в дальнейшем.

Надайсчяйская часть кембрия, которая представлена в разрезе Прибалтики очень фрагментарно и погоризонтное подразделение которой еще не разработано, коррелируется со стратиграфическими единицами общей шкалы через трилобитовую зональность, установленную в северозападных районах платформы (Martinsson, 1974; Lendzion, 1983). Для среднего кембрия наиболее совместимыми с интервалом 5-6 млн. лет являются, видимо, три надзоны, получившие названия по представителям семейства Paradoxididae: Eccoparadoxides oelandicus, Paradoxides paradoxissimus и P. forhhammeri. И хотя корреляция конкретных геологических тел с этими биостратиграфическими подразделениями еще весьма условна, все же в ней видится наиболее реальный путь решения нашей задачи.

Для позднего кембрия с предполагаемой продолжительностью 18 млн. лет целесообразно расчленение также на три хроноинтервала в объеме две трилобитовые зоны в каждом: Agnostus + Homagnostus; Parabolina spinulosa + Leptoplastus; Peltura + Acerocara.

Полученная таким путем схема убедительно демонстрирует большое значение перерывов в процессе формирования терригенных толщ: объем стратиграфических пробелов в координатах геологического времени существенно превышает объем реально сохранившихся отложений. Фактически это соотношение сдвинуто в направлении отсутствия отложений еще больше, так как и изображенные геологические тела таят в себе мпого мелких пробелов, еще невыявленных или просто немасштабных для изображения на данном рисунке. Кроме того, надо учитывать фактор неоднократного переотложения больших масс обломочного материала, так как в качестве реального геологического стратона фиксируется лишь конечный момент отложения на дне водоема, который может быть мизерным относительно времени существования данного бассейна.

Тем не менее такое изображение наглядно передает основные клас- 
сы иерархизации пробелов и характеризует их основные особенности. Так, из приведенного рисунка явствует, что крупный мега- или даже гигапробел, наблюдаемый в основании осадочного разреза Прибалтики, неоспоримо имеет региональное распространение по всей платформе. Выделяемые по данной классификации макропробелы - три в разрезе венда и кембрия - ограничиваются в основном отдельными структурнофациальными районами с одинаковой историей геологического развития. Следующий класс пробелов - мезопробел - разграничивает осадочные серии и имеет с ними аналогичное территориальное распространение. Порой они охватывают несколько структурно-фациальных районов и пространственно обычно переходят в пробелы более высокого ранга. В этой закономерности проявляет себя один из парадоксов данной области исследований: таксон, более низкий по рангу может иметь ареал распространения шире, чем более высокий по рангу. Объясняется это, видимо, качественным различием: если в возникновении макропробелов в разрезе существенную роль играют тектонические особенности развития территории, вернее - дифференциация района на отдельные блоки с различной амплитудой вертикальных движений и среза денудации, то в образовании мезопробелов - седиментационные особенности, прежде всего возникновение, развитие и исчезновение бассейнов, контролируемые менее дифференцированными тектоническими, а иногда и локальными гидростатическими явлениями.

Следующий класс - микропробелы - приурочены уже к границам более низких стратиграфических подразделений или же развиваются внутри них. Как правило, территориальное распространение их ограничивается отдельными фациальными зонами существовавших водоемов. Более мелкие пробелы, соответствующие кратким перерывам в процессе седиментации, локализуются еще более узко (в данном сообщении они не рассматриваются - их регистрация и учет намечаются в будущем). Отметим лишь, что некоторые мелкие пробелы, обычно уже не поддающиеся фиксации биостратиграфическими методами, наиболее отчетливо выделяются именно в более глубоководных отложениях, например, в кестлаской и махуской пачках лонтоваской свиты, тогда как в прибрежных фациях они теряют свою резкость на фоне общего увеличения количества признаков прерывистой седиментации в мелководье.

Таким образом, в разрезе венда и кембрия можно выделить один гигапробел, три макропробела и не менее 11 мезопробелов (таблица).

Перечень и обозначение основных стратиграфических пробелов в разрезе венда и кембрия Прибалтики

\begin{tabular}{l|l|l}
\hline Категория $\mid$ Обозначение $\mid$ Название \\
\hline
\end{tabular}

\begin{tabular}{|c|c|}
\hline Мезопробелы & $\begin{array}{l}M e-11 \\
M e-10 \\
M e-9 \\
M e-8 \\
M e-7 \\
M e-6 \\
M e-5 \\
M e-4 \\
M e-3 \\
M e-2 \\
M e-1\end{array}$ \\
\hline Макропробелы & $\begin{array}{l}M a-I I I \\
M a-I I \\
M a-I\end{array}$ \\
\hline
\end{tabular}

Гигапробел
Предтремадокский

Предладожский

Предпетсериский

Предладушкинский

Предпаалаский

Преддейменаский

Предайсчяйский

Предливский

Предбалтнйскнй

Предворонковский

Предгдовский

Преднижнеордовикскнй Предверхнекембрийский Предсреднекембрийский 
Эти пробелы и нуждаются в первоочередном изучении, так как именно они составляют основной каркас геологических событий региона.

Анализ представленного матернала свидетельствует о том, что распределение по временной шкале конкретных осадочных толщ и стратиграфических пробелов между ними явление не случайное, а закономерное. Так, отчетливо выделяются две части разреза. Первая из них охватывает венд, нижний кембрий и кибартайский горизонт среднего кембрия, вторая - посткибартайские песчаные толщи среднего и верхнего кембрия. Для первой части характерно наличие осадочных толщ с более развернутым фациальным профилем, начиная с субконтинентальнолиторальных и кончая глинистыми отложениями сравнительно спокойных участков седиментации. Пробелы между этими толщами, обусловленные континентальными перерывами в седиментации, разделяют разрез на крупные местные стратоны - серии, в пределах которых более мелкие подразделения - свиты и пачки - находятся в тесных генетических взаимоотношениях, имея одинаковый структурный план и близкие условия формирования. Пробелы между сериями (мезопробелы по нашей классификации) отчетливо отражают циклическое строение разреза и, что самое интересное, имеют определенный объем относительно реальных тел. Как видно из рисунка, объем этих пробелов в большинстве случаев около двух хроноеднниц, в то время как разделяемые ими геологические тела обычно охватывают 3-4 такие единицы. Эта закономерность настолько выдержана в вендско-нижнекембрийском разрезе региона, что ее никак нельзя считать случайностью. Поэтому понятие «серия» именно в таком смысле заслуживает должного внимания в стратиграфической таксономии.

Иначе обстоит дело с вышележащей частью разреза, в которой терригенные отложения представлены фациально более узкой гаммой отложений - преимушественно литорально-мелкошельфовыми песчаниками и алевролитами. Здесь подразделения ранга серии не выделяются, все строение осадочного комплекса напоминает сочетание геологических тел, случайно сохранившихся от неоднократных перерывов и последующих денудаций. Пробелы между фрагментарно сохранившимися осадочными образованиями не имеют выдержанного по площади характера и могут быть отнесены к разным классам, чаще всего к классу макропробелов (рисунок). Следовательно, циклическое строение разреза здесь не выявляется.

Особый интерес в разрезе венда и кембрия представляют пробелы, с которыми связаны маломощные коры и зоны выветривания осадпчных пород. Оказывается, что сохранившиеся следы выветривания, обычно проявляюшиеся в виле зоны импрегнации пород тонкодисперсным гетитом (обохривание), связаны далеко не с крvпными ппобелами. Наобопот, можно даже отметить, что такие пробелы в субконтинентальном разрезе венда (гловская и воронковская свиты) относятся к категории нано- и пикопробелов. Они обычно имеют мощность $20-30$ см и не обнарvживают выше этой зоны отчетливой поверхности размыва или изменения фациального облика пород. По-видимому, многие явления такого типа являются следствием кратковременного выхода этих пород из-под воды в зону аэрации с последующим новым погружением в зону осадконакопления. В принципе такими же являются некоторые проявления обохривания и в нормально-морских отложениях лонтоваской свиты, в которых, однако, нередко наблюдаются и явные признаки размыва неровные поверхности денудации, перекрытие их прослоями микститовых пород и др. К такому типу проявлений выветривания относятся и зоны обохривания внутри ровенского и лонтоваского горизонтов в ЮгоВосточной Литве (Коркутис, 1971; Григялис и др.. 1971), которые могут быть рассмотрены как микропробелы (рисунок). На кратковременность 
формирования этих зон обохривания указывают многие признаки, прежде всего их небольшая мощность (первые десятки сантиметров) и отсутствие какой-либо зональности в строении.

Две коры выветривания, обладающие уже более значительной мощностью $(2,5-7$ м) и признаками вертикальной зональности, связаны, по предлагаемой классификации, в основном с мезопробелами. Это охристая кора выветривания на ляминаритовых глинах котлинской свиты (Менс, Пиррус, 1969, 1970) и кора на алевритовых глинах петсериской свиты верхнего кембрия в разрезе Мехикоорма (Волкова и др., 1981). Сохранению таких зон в разрезе способствовали, видимо, специфические условия. Для надкотлинской коры характерна небольшая длительность формирования, судя по минералогическим данным (Менс, Пиррус, 1970). Отсюда, по всей вероятности, и хорошая сохранность на большой площади распространения. Для коры выветривания на петсериской свите условия сложились другие, перерыв в седиментации был более длительным, процессы денудации имели более широкий размах и, как следствие этого, соответствующая кора выветривания пока установлена лишь в одном разрезе и представлена там только своей нижней частью.

Несколько иной облик имеет третья кора выветривания, регионально более выдержанная как по своему распространению, так и по зональности строения. На востоке она формировалась на люнтоваской свите и перекрывалась среднекембрийскими песчаниками. K западу эта кора продолжается на люкатиской и, вероятно, на тискреской свитах и перекрывается уже отложениями айсчяйской серии раннего кембрия. Следовательно, пробел над этой корой,относится к разным категориям на разной территории - то к макро-, то к мезопробелу (рисунок). Различия во временном охвате пробела сопровождаются изменениями и в строении коры, в частности, в полноте ее зонального профиля. Так. к макропробелу приурочены профили с каолинитовой зоной коры выветривания, к мезопробелу - лишь обохренно-окисленные породы, представляющие либо более кратковременные образования, либо сохранившиеся «корни» полного профиля выветривания.

В итоге следvет отметить, что при длительных перерывах (наличие крупного пробела) кора выветривания на осадочных породах может развиваться наиболее полно, однако шансы на сохранение ее в конечном разрезе минимальны из-за большой роли сопровождающих денудационных процесспв. Кратковпеменные зоны аэрации - следы обохривания пород, связанные с небольшими стратиграфическими пробелами, лучше фиксируются в осадочной толще и они весьма часто встречаются в разрезах венда и кембрия рассматриваемого региона.

Второй крvг вопросов, связанный с типами пробелов в разрезе, заключается в отражении характера пробела в базальных слоях перекрывающих отложений. Это, прежде всего, проблема базальных конгломератов и скоплений наиболее крупнообломочного материала вообе. Следует сразу же отметить, что прослои конгломератов в нашем разрезе не очень характерны для уровней, залегающих непосредственно над поверхностью перерыва. Очень часто более выразительные конгломепатовые образования связаны с внутристратоновыми микро- и нанопробелами, маркируя поверхности кратковременных локальных перерывов в осадконакоплении. Сюда относятся, в частности, большинство скоплений фосфатизированных галек алевролита, наблюдаемых на многих уровнях лонтоваской, люкатиской, ирбенской, кибартайской и др. свит. Однако некоторые конгломераты такого типа встречаются и на границах стратонов, например, над мезопробелом между лонтоваской и люкатиской свитами (Лоог и др., 1966; Менс, Пиррус, 1975), над микропробелом между люкатиской и тискреской свитами (Менс, Пиррус, 1977) и др. При этом 
характерно, что такие конгломераты часто не образуют целостного прослоя над поверхностью перерыва, а представляют отдельные линзы, иногда поднимающиеся гораздо выше поверхности основного перерыва. Характерен факт, что материал галек в конгломерате часто происходит из разных уровней нижележащей или даже отсутствующей частей разреза, нередко и из слоев конгломерата более древнего происхождения (Менс, Пиррус, 1975). Настоящие базальные конгломераты установлены в сравнительно редких случаях и они обычно имеют незначительную мощность. Можно отметить, например, базальный гравелит на границе гдовской и воронковской свит в скв. Таадиквере и прослой базального конгломерата вакиской свиты в скв. Элва. Однако такого выразительного базального конгломерата, как это наблюдается в основании тремадока (Мююрисепп, 1958), в разрезах венда и кембрия пока не установлено. Парадоксально, но гораздо чаще в нашем разрезе можно найти контакты однотипных пород: глины на глинах, алевролиты на алевролитах и т. п., которые, несмотря на существенные пробелы между соответствующими комплексами пород, внешне весьма сходны и различаются иногда лишь по палеонтологическим или минералогическим характеристикам (Менс, 1979). В этом, видимо, заключается один из ведущих законов осадконакопления в платформенных условиях - дефицитность грубообломочного осадочного материала для маркирования начальной фазы трансгрессии при сильно выравненном рельефе поверхностей перерывов.

С этим хорошо согласуются имеющиеся данные по распределению крупнообломочной составляющей в разрезе (Pirrus, Rätsep, 1977): она в заметном количестве присутствует в валдайской серии (гдовская свита), в низах балтийской серии (лонтоваская и воозиская свиты), в сыруской свите ливской серии - т. е. в тех случаях, когда эти литотела на больших площадях еще контактируют с кристаллическим основанием или, другими словами, когда под ним устанавливается наличие регионалльно выраженного гигапробела. После экранизации кристаллического основания осадочным покровом к середине ливского этапа осадконакопления материала крупнее крупного песка $(>0,5$ мм) в отложениях кембрия стало уже очень мало, несмотря на то, что гидродинамические условия, позволяющие его накопление, возникали тут неоднократно (фосфатные гальки, окатыши глин и др.).

Малое развитие базальных конгломератов, большая территориальная выдержанность терригенных литотел, отсутствие крупных долин или карманообразных углублений в подошве слоев - все эти признаки однозначно говорят о том, что, несмотря на пестроту и множество пробелов в разрезе, почти все поверхности перерывов в венде и кембрии выравнивались до плоских пенепленов и не оставляли резких ступеней в рельефе до осаждения последующих осадков. Это, видимо, одна из характерных черт осадконакопления рассматриваемых терригенных толщ во всем северо-западном регионе платформы.

\section{ЛИТЕ РА Т УРА}

Брангулис А., Кала Э., Мардла А., Менс К., Пиррус Э., Сакалаускас В., Фридрихсоне А., Янкаускас $T$. Схема структурно-фациального районировання территорин Прибалтики в венде и кембрии. - Изв. АН ЭССР. Хим. Геол., 1974, 23, № 3, $218-$ 225.

Волкова Н., Каяк К., Менс К., Пиррус Э. Новые данные о переходных слоях между кембрием и ордовиком на востоке Прибалтики. - Изв. АН ЭССР. Геол., 1981, 30 , № 2, 51-55. 
Григялис А. А., Игнатавичюс В. И., Саладжюс В. Ю. Стратиграфнческне схемы и легенда геологических и гидрогеологических карт Литовской ССР. Вильнюс, 1971.

Коркутис В. А. Кембрийские отложения Балтийского бассейна. - Тр. ЛитНИГРИ, вып. 12. Вильнюс, 1971.

Лоог A., Менс K., Мююрисепn K. О границе лонтоваской и пиритаской свит нижнего кембрия Прибалтики. - Изв. АН ЭССР. Сер. физ.-мат. и техн. наук, 1966, 15, № 2, 271-276.

Менс К. Минералогическая и палеонтологическая характериєтика соэлаской свиты. Изв. АН ЭССР. Геол., 1979, 28, № 4, 125-132.

Менс $K$. Об этапности осадконакопления в раннем кембрии Прибалтики. - Изв. АН СССР. Сер. геол., 1981, № 3, 82-90.

Менс K., Пиррус Э. Древняя кора выветривания ляминаритовых глин на Северо-Западе Русской платформы. I. Распространение, морфология и зональность строения. Изв. АН ЭССР. Хим. Геол., 1969, 18, № 4, 385-391.

Менс К.. Пиррус Э. Древняя кора выветривания ллминаритовых глин на Северо-Западе Русской платформы. II. Характеристика химико-минералогических изменений и условия образования. - Изв. АН ЭССР. Хим. Геол., 1970, 19, № 1, 84-89.

Менс K. А., Пиррус Э. А. Базальный конгломерат люкатиской свиты нижнего кембрия Эстонии. - В кн.: Геология кристаллического фундамента и осадочного чехла Прибалтики. Рнга, 1975, 132-143.

Менс К. А., Пиррус Э. А. Стратотипические разрезы кембрия Эстонии. Таллин, 1977.

Менс К. А., Пости Э. А. Распределение и корреляционное значение органических остатков в балтийской серии Эстонии. - В кн.: Стратиграфия древнепалеозойских отложений Прибалтики. Таллин, 1984, 5-17.

Мююрисепn $K$. $K$. Характеристика нижней границы пакерортского горизонта от мыса Пакерорт до р. Сясь, - Тр. Ин-та геол. АН ЭССР, 1958, III, 55-79.

Пашкявичене Л. T. Новые данные стратиграфии ровенского горизонта в Прибалтике. В кн.: Достижения и задачи исследований по геологии Литовской ССР. Вильнюс, $1981,55-56$.

Пиррус Э., Эйнасто Р. Классификация стратиграфических пробелов и седиментационных перерывов в палеозое Прибалтики. - Изв. АН ЭССР. Геол., 1987, 36, № 1, $36-45$.

Решения Межведомственного регионального стратиграфического совещания по. разработке унифищированных стратиграфических схем Прибалтики, 1976 г. Л., 1978.

Стратиграфия верхнедокембрийских и кембрийских отложений запада Восточно-Европейской платформы. М., 1979.

Харленд У. Б., Кокс А. В., Ллевеллин П. Г., Пиктон К. А. Г., Смит А. Г., Уолтерс Р. Шкала геологического времени. М., 1985.

Lendzion. $K$. Rozwoi kambryjskich osadow platformowysh Polski. - Prace inst. geol., 1983, 105, $1-55$.

Martinsson. A. The Cambrian of Norden. - In: Cambrian of the British Isles, Norden and Spitsbergen. London, 1974, 185-283.

Pirrus, E., Rätsen, M. Kruusaterad Eesti vanimais settekivimeis. - Eesti Loodus, 1977, nr. $4,231-234$.
Ннститут геологии
Академии наук Эстонской ССР
Поступила в редакцию
13/I 1986

Kaisa MENS, E. PIRRUS

\section{LUNGAD POHJA-BALTIKUMI VENDI JA KAMBRIUMI LÅBILOIKES}

Toetudes lünkade varem koostatud hierarhilisele klassifikatsiooniskeemile on analüüsitud nende esinemissagedust, tüüpe ja iseloomu Pōhja-Balti vendi ja kambriumi terrigeenses läbilōikes. Uuritud läbilōikes on eristatud 15 suuremat lünka, mille jaotuspilt liigestab kogu läbilōike kahte ossa. Alumises osas on lüngad lốigustanud settimisprotsessi tsükliliselt: eraldatavad settekehad jaotuvad seeriatesse, mida regulaarselt lahutavad mesolüngad. Läbilōike ülemises osas on säilinud üksnes madalveelistes faatsiestes kuhjunud settekehad, millede jaotumine meso- ja makrolünkade taustal on ebaregulaarne, rohkem juhuslikku laadi, 


\section{HIATUSES IN THE EAST BALTIC VENDIAN AND CAMBRIAN SECTIONS}

Frequency of occurrence, types and character of hiatuses in Vendian and Cambrian terrigenous sections of the East Baltic area are analyzed on the basis of their hierarchic classification. In order to follow the relationships of the existing strata with these hiatuses a figure was compiled using the Baltic Cambrian correlation table (the Figure). To clear up these relationships in lateral direction the horizontal axis was divided into three parts corresponding to three regions with a different tectonic development and facial structure. For examining these relations in vertical section, the Cambrian time span was divided into periods with a duration of about 5-6 m.y. which are defined as chronointervals. 15 hiatuses of a higher rank were established (the Table). According to their arrangement, the whole section seems to fall into two parts. The lower part embracing the whole Late Vendian, Early and the lowermost part of the Early Middle Cambrian, is characterized by the occurrence of mesohiatuses separating the sedimentary series from each other. The upper part is stratigraphically less complete, mostly represented by sandy deposits of shallow-water conditions. Here macro- as well as mesohiatuses can be seen (the Figure).

The studied section is characterized by numerous weathering features: from weakly oxidized clay interbeds to weathering crusts with a distinctly zonal structure where sometimes the zone of kaolinite is observable as well. Mostly they are connected with hiatuses of a lower rank (micro- and nanohiatuses).

Breaks in sedimentation are not clearly marked by the occurrence of coarse-grained material. As usual this material has been found on the base of the overlying beds in the sections of the Vendian, Baltian and Liivian times, whereas some outcrops of the crystalline basement were situated on the source area. From the middle of the Liivian time the source area has been covered only by sedimentary rocks due to which the finds of coarsegrained material became very rare. 